\title{
SECAGEM DE SEMENTES DE SOJA EM SILO COM DISTRIBUIÇÃO RADIAL DO FLUXO DE AR. II. EFEITOS SOBRE A QUALIDADE DAS SEMENTES ${ }^{1}$
}

\author{
LUIZ CARLOS MIRANDA ${ }^{2}$, WALTER RODRIGUES DA SILVA ${ }^{3}$ e CLÁUDIO CAVARIANI ${ }^{4}$
}

\begin{abstract}
RESUMO - O trabalho avaliou, em sementes de soja, as conseqüências qualitativas provenientes da secagem estacionária com distribuição radial de ar, variando o fluxo $(26,9,28,4$ e $33,2 \mathrm{~m}$ /minuto/t) e a temperatura do ar insuflado $\left(42,46\right.$ e $\left.50^{\circ} \mathrm{C}\right)$, considerando a posição das sementes na massa $(17,34$ e $51 \mathrm{~cm}$ em relação ao cilindro de insuflação) e o tempo de secagem (0 a 12 horas, com intervalos de quatro horas). Para tanto, além das determinações das temperaturas e dos teores de água da massa, foi avaliado o desempenho físiológico das sementes no início e ao final de seis meses de armazenamento. Apesar das vantagens físicas operacionais resultantes da combinação entre o fluxo e a temperatura intermediários $\left(28,4 \mathrm{~m}^{3} /\right.$ minuto/t e $\left.46^{\circ} \mathrm{C}\right)$, a qualidade físiológica foi menos prejudicada nas combinações dos menores fluxos $\left(26,9\right.$ e $28,4 \mathrm{~m}^{3} /$ minuto/t) com a maior temperatura $\left(50^{\circ} \mathrm{C}\right)$ e do maior fluxo $\left(33,2 \mathrm{~m}^{3} /\right.$ minuto/t) com as menores temperaturas $\left(42 \mathrm{e} 46^{\circ} \mathrm{C}\right)$; entre estas, levando em conta os aspectos físico-operacionais, a associação de $28,4 \mathrm{~m}^{3} /$ minuto $/ \mathrm{t}$ com $50^{\circ} \mathrm{C}$ foi a mais eficiente na retirada de água das sementes. Assim, admitindo os intervalos de fluxo (26,9 a 33,2 m³ minuto/t) e de temperatura $\left(42 \mathrm{a} 50^{\circ} \mathrm{C}\right)$ estudados, conclui-se que a elevação na temperatura demanda redução no fluxo $\mathrm{e}$, inversamente, o aumento no fluxo demanda redução na temperatura.
\end{abstract}

Termos para indexação: processamento, qualidade fisiológica.

\section{DRYING OF SOYBEAN SEEDS IN A RADIALAIR FLOW DRYER.} II. EFFECTS ON SEED QUALITY

ABSTRACT - The purpose of the research was to evaluate the influence of combinations of air flows $\left(26.9,28.4\right.$ and $33.2 \mathrm{~m}^{3} /$ minute/ton) and temperatures $\left(42,46\right.$ and $\left.50^{\circ} \mathrm{C}\right)$ on soybean seeds quality submitted to a stationary drying process with radial air distribution considering differents seed positions in the seed mass $(17,34$ and $51 \mathrm{~cm}$ in relation to the insuflation cylinder) and four sampling periods of four hour intervals. Besides temperature and moisture content of seed mass, physiological seed quality was evaluated at the beginning and after a period of six months storage. Although the combination of the intermediates air flow and temperature $\left(28.4 \mathrm{~m}^{3} /\right.$ minute/ton and $\left.46^{\circ} \mathrm{C}\right)$ had been physically advantageous, the seed quality was less impaired by the combinations of the smaller air flows $\left(26.9\right.$ and $28.4 \mathrm{~m}^{3} /$ minute/ton) with the highest temperature $\left(50^{\circ} \mathrm{C}\right)$ and the highest air flow $\left(33.2 \mathrm{~m}^{3} /\right.$ minute/ton) with the smaller temperatures $\left(42\right.$ and $\left.46^{\circ} \mathrm{C}\right)$. Among those, the association of $28.4 \mathrm{~m}^{3} / \mathrm{min} /$ ton with $50^{\circ} \mathrm{C}$ was the most efficient in the watertaking of seeds. Thus, admitting the air flow intervals between 26.9 and $33.2 \mathrm{~m}^{3} /$ minute/ton and temperature from 42 to $50^{\circ} \mathrm{C}$, it is possible to conclude that increasing of air flow requests decreasing of temperature, and increasing of temperature requests decreasing of the air flow.

Index terms: processing, physiological quality.

${ }^{1}$ Aceito para publicação em 9 de novembro de 1998.

Extraído da Tese de Doutorado do primeiro autor, apresentada à USP-ESALQ, Piracicaba, SP.

${ }^{2}$ Eng. Agr., Dr., Embrapa-Serviço de Negócios para Transferência de Tecnologia (SNT), Caixa Postal 231, CEP 86001-970 Londrina, PR. E-mail: miranda@enpso.embrapa.br

${ }^{3}$ Eng. Agr., Dr., USP, Escola Superior de Agricultura Luiz de Queiroz, Caixa Postal 09, CEP 13418-900 Piracicaba, SP. E-mail: wrsilva@carpa.ciagri.usp.br

${ }^{4}$ Eng. Agr., Dr., Prof. Assistente, UNESP, Faculdade de Ciências Agronômicas, Caixa Postal 237, CEP 18603-970 Botucatu, SP. E-mail: secdamv@fca.unesp.br

\section{INTRODUÇÃO}

A semente, de maneira geral, quando atinge a maturidade fisiológica, apresenta qualidade representada pelos máximos poder germinativo, vigor, e peso de matéria seca; nesse ponto, apresenta teores de água, geralmente acima de $30 \%$, não compatíveis com a tecnologia disponível para a colheita mecânica e, a partir daí, permanece armazenada no campo submetida a fatores potencialmente desfavoráveis à preservação da sua qualidade. É necessária, 
portanto, a compatibilização entre o teor de água das sementes e o método de colheita empregado para reduzir ao mínimo o retardamento dessa operação em relação ao ponto de maturidade fisiológica das sementes. Como decorrência, tornam-se indispensáveis os conhecimentos sobre a secagem artificial do material colhido, para que o teor de água obtido permita o armazenamento adequado durante a entressafra.

Boyd (1974), estudando a secagem de sementes de soja em silo estacionário de fundo falso perfurado, verificou a necessidade de compatibilizar o fluxo de ar e a altura da camada de sementes, como forma de minimizar o tempo de secagem e reduzir os efeitos negativos sobre a qualidade das sementes. Relatou que temperatura de $54,4^{\circ} \mathrm{C}$ e umidade relativa inferior a $40 \%$ no ar de secagem, provocam redução na germinação; a baixa umidade relativa do ar de secagem não afetou diretamente a germinação, mas associou-se ao surgimento de rachaduras no tegumento das sementes. Verificou, também, que sementes colhidas com teores de água de $18,5 \%$ e $22,3 \%$, quando secadas até $12 \%$ utilizando fluxos de ar iguais ou superiores a $10 \mathrm{~m}^{3} /$ minuto/t e temperatura da massa de até $38^{\circ} \mathrm{C}$, não apresentaram reduções acentuadas de qualidade. Da mesma forma, Corrêa (1981), trabalhando com equipamento de distribuição radial de ar em sementes de arroz, não observou prejuízos na qualidade fisiológica das sementes quando empregou ar insuflado a $42^{\circ} \mathrm{C}$, em massa com $1,35 \mathrm{~m}$ de espessura, durante 15 horas. A remoção de $0,3 \%$ de água por hora, sob fluxo de $5,5 \mathrm{~m}^{3} / \mathrm{minuto} / \mathrm{t}$ a $43^{\circ} \mathrm{C}$, foi sugerida por Brandenburg et al. (1961) como regra geral a ser utilizada em secagem de sementes.

Pasin (1991) observou o deslocamento da frente de secagem em sementes de soja, com teor de água inicial de $16,3 \%$, utilizando secador estacionário de tubo central perfurado, e massa de sementes com 1,35 $\mathrm{m}$ de espessura. Durante o período de secagem, nos diversos momentos de amostragem, foram verificadas as temperaturas máxima, junto ao tubo central perfurado $\left(41^{\circ} \mathrm{C}\right)$, e mínima, junto à parede externa do secador $\left(26^{\circ} \mathrm{C}\right)$, apresentando gradiente de $15^{\circ} \mathrm{C}$. O teor de água das sementes, durante o deslocamento da frente de secagem, apresentou variação de $3,7 \%$, estando as sementes mais secas
$(9,5 \%)$ próximas ao tubo central perfurado e as mais úmidas $(13,2 \%)$ próximas à parede externa do secador. Segundo o autor, esse gradiente não afeta a qualidade das sementes, e tende a desaparecer pela ação do sistema de descarga em camadas, desenvolvido para esse tipo de secador, que garante a homogeneização da massa de sementes.

A sensibilidade fisiológica ao dano térmico é, segundo diferentes autores, função da espécie, do genótipo, do teor de água, da temperatura, do tempo de exposição e da velocidade de secagem (Navratil \& Burris, 1984; Herter \& Burris, 1989b). A causa primária do dano fisiológico produzido por altas temperaturas em tecidos vegetais é, conforme Daniell et al. (1969), a desestruturação das membranas celulares, possivelmente por alterações nos lipídios que as constituem. Paralelamente, é aceita a teoria de que o calor excessivo provoca, entre outras alterações, a desnaturação de proteínas. Segundo Herter \& Burris (1989a), danos térmicos às sementes de soja são caracterizados quando promovem a ruptura em ligações peptídicas de proteínas e de outros componentes celulares, e já foi constatado que o início do efeito deletério durante secagem à alta temperatura coincidiu com o início da secagem do embrião; contudo, não foi possível concluir se a perda de água do embrião é a causa fundamental do dano. Esses danos podem, ainda, atingir sistemas subcelulares, incluindo cromossomos (Roberts, 1972, 1981) e mitocôndrios (França Neto, 1984); acham-se associados à redução do número de grãos de amido no eixo embrionário, aos aumentos de lixiviação de eletrólitos e açúcares e de produção de pigmentos carotenóides (Seyedin et al., 1984), e às alterações na permeabilidade de membranas celulares (Seyedin et al., 1984; Herter \& Burris, 1989c).

Koster \& Leopold (1988), secando sementes de soja até $8 \% \mathrm{H}_{2} \mathrm{O}$ b.s., teor considerado prejudicial aos tecidos sensíveis à desidratação, verificaram que a tolerância à perda de água foi negativamente afetada quando houve lixiviação de oligossacarídeos tidos como preventivos da cristalização da sacarose; esta, em sua forma não-cristalizada, participa da estabilização estrutural das membranas celulares mantendo sua hidratação. Paralelamente, houve aumento no teor de monossacarídeos redutores nos 
eixos embrionários que, potencialmente, causam danos às proteínas e aos ácidos nucléicos, afetando a viabilidade das sementes. Chen \& Burris (1990) concluíram que, além da sacarose, a rafinose atua na estabilização das membranas e contribui para a tolerância à secagem. Essas constatações concordam com as de Koster \& Leopold (1988), que verificaram, após o armazenamento, que as sementes de soja com $96 \%$ de germinação continham sacarose e rafinose, as com $12 \%$ continham apenas sacarose e, as que não germinaram continham glucose e frutose em lugar de sacarose e rafinose.

O presente trabalho destinou-se ao estudo das relações existentes entre o rendimento operacional com a manutenção da qualidade fisiológica das sementes.

\section{MATERIAL E MÉTODOS}

Foram utilizadas sementes de soja da cultivar EMBRAPA 4 (BR $4 \mathrm{RC}$ ), produzidas em Ponta Grossa, PR na safra 1994/95. A colheita, o processamento e a obtenção dos tratamentos foram conduzidos conforme método descrito por Miranda et al. (1999).

A amostragem foi realizada em intervalos de quatro horas, para a aferição da qualidade das sementes durante o armazenamento.

A temperatura $\left({ }^{\circ} \mathrm{C}\right)$ da massa de sementes foi obtida com aparelho digital da marca Entag, equipado com pares termoelétricos, com leituras em todos os pontos de amostragem das sementes; a temperatura, referente a cada uma das três distâncias consideradas em relação ao tubo central de insuflação de ar, foi representada pela média das temperaturas obtidas nas três alturas $\left(\mathrm{H}_{1}, \mathrm{H}_{2}, \mathrm{H}_{3}\right)$.

Após a obtenção do material correspondente às combinações fluxo/temperatura, distâncias e períodos de secagem, cada amostra foi homogeneizada e subdividida em duas frações que foram mantidas em câmara fria e seca $\left(5^{\circ} \mathrm{C}\right.$ e $40 \%$ U.R.), para uniformização do teor de água, por um período de 60 dias; após esse período foram transferidas para condições não-controladas de ambiente, em armazém convencional. Essa ocasião correspondeu ao início do armazenamento que foi estudado, quanto às variações na qualidade fisiológica das sementes, aos zero e seis meses.

Foram conduzidas as seguintes determinações, no início (efeitos imediatos) e ao final (efeitos latentes) do período de armazenamento: teor (\%) de água das sementes, utilizando o método da estufa a $105^{\circ} \mathrm{C} \pm 3^{\circ} \mathrm{C}$, durante 24 horas, conforme Brasil (1992); teste de germinação
(\%), conduzido a $25^{\circ} \mathrm{C}$, em quatro subamostras de 50 sementes por repetição conforme os procedimentos descritos em Brasil (1992); teste de condutividade elétrica $(\mu \mathrm{A} /$ semente), realizado em duas subamostras de 100 sementes, por repetição, colocadas para embeber em recipientes de plástico contendo uma célula para cada semente submersa em água destilada a $20^{\circ} \mathrm{C}$, por 24 horas, a $20^{\circ} \mathrm{C}$. Seguiu-se a leitura em condutivímetro modelo ASA 610, e o resultado foi expresso em porcentagem de sementes viáveis, tendo como referência o ponto de partição $90 \mu \mathrm{A} /$ semente, seguindo-se os demais procedimentos recomendados no manual do equipamento (Agro Sciences, 1979) e a metodologia descrita por Dias (1994); teste de tetrazólio (\%), empregando duas subamostras de 50 sementes por repetição, pré-condicionadas a $25^{\circ} \mathrm{C} \mathrm{em}$ papel toalha umedecido com água, por 16 horas. Após esse período, as sementes foram colocadas em copos-becker e submersas em solução de tetrazólio a $0,075 \%$ por 150 a 180 minutos, à temperatura de $35-40^{\circ} \mathrm{C}$. As sementes foram então lavadas e mantidas submersas em água até o momento da avaliação, obtendo-se leituras de viabilidade (TZG\%) e de vigor (TZV\%), segundo os critérios descritos por França Neto et al. (1988); teste de envelhecimento acelerado (\%), executado conforme metodologia descrita por Marcos Filho (1994), consistiu na utilização de caixas gerbox como compartimento individual (minicâmaras), possuindo, no seu interior, uma bandeja de tela de aço inox, sobre a qual foram distribuídas as sementes. Essas minicâmaras foram mantidas a $42^{\circ} \mathrm{C}$, após a adição de $40 \mathrm{~mL}$ de água em seu interior, durante 48 horas. Após esse período, as sementes foram submetidas ao teste de germinação, utilizando-se quatro subamostras de 50 sementes por repetição e interpretação após quatro dias de permanência no germinador; teste de emergência de plântulas (\%), realizado em casa de vegetação sob $20^{\circ} \mathrm{C}$ e disponibilidade hídrica mantida na capacidade de campo. Foram utilizadas 50 sementes por repetição, que, por sua vez, foram instaladas em bandejas contendo, como substrato, uma mistura não-esterilizada de $70 \%$ de solo Latossolo Roxo distrófico e $30 \%$ de areia. A contagem, efetuada aos 14 dias após a semeadura, considerou as plântulas emersas em qualquer estádio de desenvolvimento; testes de comprimento da raiz e da plântula $(\mathrm{cm})$, realizados conjuntamente, utilizando quatro subamostras de dez sementes, por repetição, colocadas manualmente no terço superior do papel toalha, com o hilo voltado para a parte inferior. Os rolos de papel, umedecidos com 2,25 vezes o seu peso em água, foram mantidos inclinados $\left(45^{\circ}\right)$ no germinador, em ausência de luz a $25^{\circ} \mathrm{C}$, durante cinco dias. No final desse período, considerando exclusivamente as plântulas 
normais (Brasil, 1992), foram medidos os comprimentos da raiz (extremidade da raiz à região de transição entre o hipocótilo e a raiz) e da plântula (extremidade da raiz ao ponto de inserção dos cotilédones).

A análise dos dados de avaliação da qualidade das sementes, com exceção dos relativos ao teor de água que não foram estatisticamente analisados, considerou separadamente os efeitos de fluxo $(\mathrm{F}) \mathrm{x}$ temperatura $(\mathrm{T})$ e de distância (D) x tempo de secagem (TS).

Os efeitos de distância $\mathrm{x}$ tempo de secagem foram analisados, preliminarmente, em cada combinação F x T. Constatadas diferenças aceitáveis entre valores extremos dos quadrados médios residuais, optou-se por análise conjunta reunindo dados de todas as combinações de fluxo x temperatura. De modo similar, os efeitos de fluxo $\mathrm{x}$ temperatura, após o estudo dos valores extremos dos quadrados médios residuais obtidos em análise prévia para cada combinação D x TS, passaram por análise conjunta reunindo as combinações de distância $\mathrm{x}$ tempo de secagem.

Quando a interação entre os fatores revelou-se significativa, foram realizados os desdobramentos dos graus de liberdade dos quadrados médios, e aplicado o teste de Tukey, a 5\% de probabilidade, para a comparação entre médias.

\section{RESULTADOS E DISCUSSÃO}

O teor de água das sementes (Tabela 1) apresentou, fixados os períodos de armazenamento, variações em seus valores. No entanto, quando verificados os dados médios obtidos por tratamento, as diferenças foram reduzidas, e não sugeriram a existência de efeitos relacionados aos tratamentos, capazes de interferir na interpretação dos dados fisiológicos.

Os testes fisiológicos utilizados não foram completamente uniformes nas indicações fornecidas sobre os tratamentos, o que confirma o relatado por Cavariani (1996) quanto à dificuldade existente para a escolha de determinações voltadas à estimativa da qualidade fisiológica em sementes. As Tabelas 2 e 3 apresentam os dados fisiológicos relativos aos efeitos imediatos (0 mês) e latentes (seis meses), obtidos no armazenamento, e relacionados às variações nas distâncias e nos tempos de secagem.

Fixados os tempos de secagem, foram observadas, considerando os efeitos imediatos ( 0 mês), tendências de redução qualitativa com a ampliação da distância, no período operacional de quatro horas, pelos testes de germinação, de envelhecimento acelerado e de emergência; contudo, ampliado o período de secagem, esse fato foi detectado exclusivamente pelos testes de envelhecimento acelerado (quatro horas) e de germinação (12 horas). Por outro lado, quando verificados os efeitos latentes, tendências idênticas foram invariavelmente constatadas, em todos os tempos operacionais, pelos testes de tetrazólio (germinação), e de comprimentos de raiz e de plântula apontando prejuízos fisiológicos às sementes das maiores distâncias. Assim, apesar de não se apresentar em todas as avaliações realizadas, essa constatação indica resultados, em relação aos efeitos provenientes do posicionamento na massa, contrários aos encontrados em secagens estacionárias com distribuições radial (McLean, 1980; Corrêa, 1981; Pasin, 1991; Cavariani, 1996). Vale destacar, contudo, que essa indicação foi observada, inclusive, em quatro das determinações realizadas no material que não havia sido submetido à secagem (0 hora), fato que, em contrapartida, atua reduzindo a validade da interpretação formulada.

Quando fixadas as distâncias, os efeitos imediatos e latentes obtidos no conjunto dos testes foram desordenados, e não sugeriram tendências consistentes relacionadas aos períodos de secagem.

A combinação de valores elevados, na temperatura e no teor de água das sementes, é reconhecida como prejudicial à qualidade fisiológica (Boyd, 1974; Brooker et al., 1974; Lasseran, 1978; Carvalho, 1994). Verificou-se relação inversa da temperatura com o teor de água das sementes que, invariavelmente, mostrou associação entre a eficiência da secagem, com a capacidade de acelerar o aquecimento da massa. Embora a massa tenha atingido valores superiores ao de $43^{\circ} \mathrm{C}$ recomendado como limite máximo na secagem de sementes de soja (Villa \& Roa, 1979; Peske \& Baudet, 1980; Peske \& Aguirre, 1987), em vários casos que envolveram as distâncias $\mathrm{D}_{1}$ e $\mathrm{D}_{2}$, nas maiores temperaturas do ar insuflado (Tabela 4), as sementes fisiologicamente mais prejudicadas foram as que se achavam em $\mathrm{D}_{3}$ com as menores temperaturas e, conseqüentemente, com os maiores graus de umidade. Assim, verifica-se que na operação de secagem o controle da temperatura, por si só, não garante a preservação do desempenho fisiológico das sementes, e há necessidade de sua compatibilização com a eficiência física do processo. 
TABELA 1. Dados do teor (\%) de água da semente de soja, submetidas a diferentes tempos de secagem com variações no fluxo e na temperatura do ar insuflado, no início (0 mês) e no final (6 meses) do armazenamento. Ponta Grossa, PR, 1995 1.

\begin{tabular}{|c|c|c|c|c|c|c|c|c|c|c|}
\hline \multicolumn{2}{|c|}{ Tratamentos } & \multirow{3}{*}{$\begin{array}{l}\text { Tempo de } \\
\text { secagem } \\
\text { (hora) }\end{array}$} & \multicolumn{8}{|c|}{ Armazenamento } \\
\hline \multirow{2}{*}{$\begin{array}{c}\mathrm{T} \\
\left({ }^{\circ} \mathrm{C}\right) \\
\end{array}$} & \multirow{2}{*}{$\begin{array}{c}\mathrm{F} \\
\left(\mathrm{m}^{3} / \text { minuto/t }\right) \\
\end{array}$} & & \multicolumn{4}{|c|}{0 mês } & \multicolumn{4}{|c|}{6 meses } \\
\hline & & & $\mathrm{D}_{1}$ & $\mathrm{D}_{2}$ & $\mathrm{D}_{3}$ & Médias & $\mathrm{D}_{1}$ & $\mathrm{D}_{2}$ & $\mathrm{D}_{3}$ & Médias \\
\hline \multirow[t]{15}{*}{42} & 26,9 & 0 & 10,4 & 10,8 & 10,9 & 10,7 & 12,8 & 11,6 & 12,0 & 12,1 \\
\hline & & 4 & 11,1 & 10,6 & 10,9 & 10,9 & 13,1 & 12,4 & 13,1 & 12,9 \\
\hline & & 8 & 10,1 & 10,0 & 10,1 & 10,1 & 12,2 & 12,6 & 12,8 & 12,5 \\
\hline & & 12 & 10,3 & 10,6 & 10,7 & 10,5 & 12,7 & 11,1 & 11,1 & 11,6 \\
\hline & & Médias & 10,5 & 10,5 & 10,7 & 10,6 & 12,7 & 11,9 & 12,3 & 12,3 \\
\hline & 28,4 & 0 & 10,4 & 10,8 & 10,4 & 10,5 & 12,8 & 11,7 & 12,5 & 12,3 \\
\hline & & 4 & 10,4 & 10,8 & 10,4 & 10,5 & 12,8 & 13,0 & 12,0 & 12,6 \\
\hline & & 8 & 10,0 & 10,5 & 10,1 & 10,2 & 12,1 & 13,1 & 13,1 & 12,8 \\
\hline & & 12 & 10,5 & 10,5 & 10,3 & 10,4 & 12,9 & 13,1 & 13,7 & 13,2 \\
\hline & & Médias & 10,3 & 10,7 & 10,3 & 10,4 & 12,7 & 12,7 & 12,8 & 12,7 \\
\hline & 33,2 & 0 & 10,0 & 10,5 & 10,4 & 10,3 & 12,7 & 11,8 & 12,9 & 12,5 \\
\hline & & 4 & 10,6 & 11,3 & 11,0 & 11,0 & 13,0 & 12,7 & 12,5 & 12,7 \\
\hline & & 8 & 10,0 & 10,2 & 10,2 & 10,1 & 13,1 & 13,9 & 13,7 & 13,6 \\
\hline & & 12 & 10,0 & 10,4 & 10,5 & 10,3 & 13,0 & 12,4 & 13,8 & 13,1 \\
\hline & & Médias & 10,2 & 10,6 & 10,5 & 10,4 & 13,0 & 12,7 & 13,2 & 13,0 \\
\hline \multirow[t]{15}{*}{46} & 26,9 & 0 & 11,0 & 10,5 & 10,5 & 10,7 & 12,7 & 13,1 & 12,8 & 12,9 \\
\hline & & 4 & 10,1 & 10,5 & 10,1 & 10,2 & 11,6 & 11,6 & 13,3 & 12,2 \\
\hline & & 8 & 10,0 & 10,2 & 10,2 & 10,1 & 11,9 & 11,6 & 12,3 & 11,9 \\
\hline & & 12 & 10,1 & 10,3 & 10,3 & 10,2 & 13,9 & 13,5 & 12,5 & 13,3 \\
\hline & & Médias & 10,3 & 10,4 & 10,3 & 10,3 & 12,5 & 12,5 & 12,7 & 12,6 \\
\hline & 28,4 & 0 & 10,5 & 10,6 & 10,1 & 10,4 & 12,7 & 12,8 & 13,0 & 12,8 \\
\hline & & 4 & 10,5 & 10,3 & 11,0 & 10,6 & 10,3 & 11,6 & 12,9 & 11,6 \\
\hline & & 8 & 10,7 & 11,0 & 10,7 & 10,8 & 11,7 & 12,2 & 12,6 & 12,2 \\
\hline & & 12 & 9,9 & 10,4 & 10,5 & 10,3 & 12,7 & 11,4 & 13,4 & 12,5 \\
\hline & & Médias & 10,4 & 10,6 & 10,6 & 10,5 & 11,9 & 12,0 & 13,0 & 12,3 \\
\hline & 33,2 & 0 & 10,9 & 10,7 & 10,6 & 10,7 & 12,6 & 13,1 & 12,9 & 12,9 \\
\hline & & 4 & 9,8 & 10,0 & 10,2 & 10,0 & 11,3 & 12,6 & 13,7 & 12,5 \\
\hline & & 8 & 9,4 & 9,9 & 9,9 & 9,7 & 12,8 & 10,1 & 11,7 & 11,5 \\
\hline & & 12 & 9,4 & 9,5 & 9,7 & 9,5 & 12,5 & 11,9 & 11,4 & 11,9 \\
\hline & & Médias & 9,9 & 10,1 & 10,1 & 10,0 & 12,3 & 11,9 & 12,4 & 12,2 \\
\hline \multirow[t]{15}{*}{50} & 26,9 & 0 & 10,6 & 10,9 & 10,9 & 10,8 & 12,9 & 12,3 & 12,7 & 12,6 \\
\hline & & 4 & 10,1 & 11,6 & 11,1 & 10.9 & 13,4 & 11,5 & 12,9 & 12,6 \\
\hline & & 8 & 9,4 & 9,9 & 10,2 & 9,8 & 11,7 & 11,3 & 12,8 & 11,9 \\
\hline & & 12 & 9,7 & 9,9 & 10,1 & 9,9 & 13,4 & 11,9 & 11,0 & 12,1 \\
\hline & & Médias & 10,0 & 10,6 & 10,6 & 10,4 & 12,9 & 11,8 & 12,4 & 12,3 \\
\hline & 28,4 & 0 & 10,5 & 10,4 & 10,4 & 10,4 & 12,9 & 11,3 & 10,3 & 11,5 \\
\hline & & 4 & 10,2 & 10,5 & 10,9 & 10,5 & 12,1 & 12,5 & 13,8 & 12,8 \\
\hline & & 8 & 9,9 & 10,1 & 10,1 & 10,0 & 12,8 & 12,6 & 11,4 & 12,3 \\
\hline & & 12 & 9,6 & 10,0 & 10,1 & 9,9 & 12,6 & 13,3 & 12,4 & 12,8 \\
\hline & & Médias & 10,1 & 10,3 & 10,4 & 10,2 & 12,6 & 12,4 & 12,0 & 12,3 \\
\hline & 33,2 & 0 & 10,3 & 9,2 & 9,6 & 9,7 & 13,0 & 10,9 & 11,6 & 11,8 \\
\hline & & 4 & 9,5 & 9,6 & 9,8 & 9,6 & 11,9 & 11,7 & 10,4 & 11,3 \\
\hline & & 8 & 9,8 & 10,3 & 9,9 & 10,0 & 12,0 & 13,2 & 13,4 & 12,9 \\
\hline & & 12 & 9,2 & 9,2 & 9,2 & 9,2 & 10,7 & 13,0 & 12,9 & 12,2 \\
\hline & & Médias & 9,7 & 9,6 & 9,6 & 9,6 & 11,9 & 12,2 & 12,1 & 12,1 \\
\hline
\end{tabular}

${ }^{1}$ T: temperatura; F: fluxo de ar insuflado; D1, D2, D3: distâncias radiais em relação ao cilindro central de insuflação de ar. 
TABELA 2. Testes de germinação (G\%), de condutividade elétrica (CE G\%), de tetrazólio germinação (TZG\%) e de tetrazólio vigor (TZV\%): dados médios, considerando as distâncias à entrada do ar insuflado e o tempo de secagem, em sementes de soja submetidas ao armazenamento. Ponta Grossa, PR, $1995^{1}$.

\begin{tabular}{|c|c|c|c|c|c|c|c|c|c|}
\hline \multirow[t]{3}{*}{ Teste } & \multirow{3}{*}{$\begin{array}{c}\text { Tempo de } \\
\text { secagem } \\
\text { (hora) }\end{array}$} & \multicolumn{4}{|c|}{0 mês } & \multicolumn{4}{|c|}{6 meses } \\
\hline & & \multicolumn{3}{|c|}{ Distâncias } & \multirow[b]{2}{*}{ Médias } & \multicolumn{3}{|c|}{ Distâncias } & \multirow[b]{2}{*}{ Médias } \\
\hline & & $\mathrm{D}_{1}$ & $\mathrm{D}_{2}$ & $\mathrm{D}_{3}$ & & $\mathrm{D}_{1}$ & $\mathrm{D}_{2}$ & $\mathrm{D}_{3}$ & \\
\hline \multirow[t]{5}{*}{$\mathrm{G} \%$} & 0 & $89,1 \mathrm{Aa}$ & $88,6 \mathrm{Aa}$ & $88,5 \mathrm{Aa}$ & $88,8 \mathrm{~A}$ & $86,7 \mathrm{Aa}$ & $86,5 \mathrm{Ba}$ & $86,5 \mathrm{ABa}$ & $86,6 \mathrm{~B}$ \\
\hline & 4 & $89,4 \mathrm{Aab}$ & $90,0 \mathrm{Aa}$ & $88,1 \mathrm{Ab}$ & $89,2 \mathrm{~A}$ & $87,6 \mathrm{Aab}$ & $88,5 \mathrm{Aa}$ & $85,9 \mathrm{Bb}$ & $87,3 \mathrm{AB}$ \\
\hline & 8 & $90,0 \mathrm{Aa}$ & 89,9Aa & $88,5 \mathrm{Aa}$ & $89,5 \mathrm{~A}$ & $87,3 \mathrm{Aa}$ & $88,1 \mathrm{ABa}$ & $86,7 \mathrm{ABa}$ & $87,4 \mathrm{AB}$ \\
\hline & 12 & $90,5 \mathrm{Aa}$ & $89,4 \mathrm{Aab}$ & $88,7 \mathrm{Ab}$ & $89,6 \mathrm{~A}$ & $87,7 \mathrm{Aa}$ & $87,4 \mathrm{ABa}$ & 87,7Aa & $87,6 \mathrm{~A}$ \\
\hline & Médias & $89,8 \mathrm{a}$ & $89,5 \mathrm{a}$ & $88,5 b$ & 89,3 & $87,3 \mathrm{a}$ & $87,6 \mathrm{a}$ & $86,7 \mathrm{a}$ & 87,2 \\
\hline \multirow[t]{5}{*}{ CE G \% } & 0 & $88,5 \mathrm{Aa}$ & $88,1 \mathrm{Aa}$ & $88,5 \mathrm{Aa}$ & $88,4 \mathrm{~A}$ & $83,8 \mathrm{Aa}$ & $82,1 \mathrm{Aa}$ & $82,9 \mathrm{Aa}$ & $82,9 \mathrm{~A}$ \\
\hline & 4 & $89,3 \mathrm{Aa}$ & $89,7 \mathrm{Aa}$ & $87,7 \mathrm{Aa}$ & $88,9 \mathrm{~A}$ & $86,3 \mathrm{Aa}$ & $83,4 \mathrm{Ab}$ & $82,6 \mathrm{Ab}$ & $84,1 \mathrm{~A}$ \\
\hline & 8 & $89,0 \mathrm{Aa}$ & $89,6 \mathrm{Aa}$ & $87,7 \mathrm{Aa}$ & $88,8 \mathrm{~A}$ & $84,9 \mathrm{Aa}$ & $83,7 \mathrm{Aa}$ & $84,7 \mathrm{Aa}$ & $84,4 \mathrm{~A}$ \\
\hline & 12 & $89,3 \mathrm{Aa}$ & $90,4 \mathrm{Aa}$ & $89,1 \mathrm{Aa}$ & $89,6 \mathrm{~A}$ & $84,5 \mathrm{Aa}$ & 82,9Aa & $84,0 \mathrm{Aa}$ & $83,8 \mathrm{~A}$ \\
\hline & Médias & $89,0 \mathrm{ab}$ & $89,4 a$ & $88,3 b$ & 88,9 & $84,9 a$ & $83,0 \mathrm{~b}$ & $83,6 b$ & 83,8 \\
\hline \multirow[t]{5}{*}{ TZG \% } & 0 & $84,5 \mathrm{Aa}$ & 83,7Aa & $84,1 \mathrm{ABa}$ & $84,1 \mathrm{~B}$ & $84,9 \mathrm{Aa}$ & $83,4 \mathrm{Aab}$ & $82,6 \mathrm{Ab}$ & $83,6 \mathrm{~A}$ \\
\hline & 4 & $84,6 \mathrm{Aa}$ & $83,8 \mathrm{Aa}$ & $83,4 \mathrm{Ba}$ & $83,9 \mathrm{~B}$ & $86,6 \mathrm{Aa}$ & $84,1 \mathrm{Ab}$ & $81,4 \mathrm{Ac}$ & $84,0 \mathrm{~A}$ \\
\hline & 8 & $86,0 \mathrm{Aa}$ & $86,0 \mathrm{Aa}$ & $86,0 \mathrm{Aa}$ & $86,0 \mathrm{~A}$ & $85,5 \mathrm{Aa}$ & $83,4 \mathrm{Aab}$ & $83,0 \mathrm{Ab}$ & $84,0 \mathrm{~A}$ \\
\hline & 12 & $85,8 \mathrm{Aa}$ & $85,0 \mathrm{Aa}$ & $84,0 \mathrm{ABa}$ & $84,9 \mathrm{AB}$ & $85,3 \mathrm{Aa}$ & 83,9Aab & $82,3 \mathrm{Ab}$ & $83,9 \mathrm{~A}$ \\
\hline & Médias & $85,2 \mathrm{a}$ & $84,6 \mathrm{a}$ & $84,4 \mathrm{a}$ & 84,7 & $85,6 \mathrm{a}$ & $83,7 \mathrm{~b}$ & $82,3 \mathrm{c}$ & 83,9 \\
\hline \multirow[t]{5}{*}{ TZV \% } & 0 & $73,5 \mathrm{Aa}$ & $73,2 \mathrm{ABa}$ & $75,4 \mathrm{Aa}$ & $74,0 \mathrm{~A}$ & 70,9Aa & $69,5 \mathrm{Aab}$ & $67,4 \mathrm{Bb}$ & $69,3 \mathrm{~A}$ \\
\hline & 4 & $73,1 \mathrm{Aa}$ & $71,1 \mathrm{Ba}$ & $70,9 \mathrm{Ba}$ & 71,7B & $73,2 \mathrm{Aa}$ & 71,9Aa & $66,8 \mathrm{Bb}$ & $70,6 \mathrm{~A}$ \\
\hline & 8 & $74,6 \mathrm{Aa}$ & $75,3 \mathrm{Aa}$ & $75,3 \mathrm{Aa}$ & $75,0 \mathrm{~A}$ & $71,2 \mathrm{Aa}$ & $69,6 \mathrm{Aa}$ & $69,8 \mathrm{Aa}$ & $70,2 \mathrm{~A}$ \\
\hline & 12 & $75,5 \mathrm{Aa}$ & $73,6 \mathrm{ABa}$ & $73,1 \mathrm{ABa}$ & $74,0 \mathrm{~A}$ & $71,2 \mathrm{Aa}$ & $69,9 \mathrm{Aa}$ & $68,8 \mathrm{ABa}$ & $70,0 \mathrm{~A}$ \\
\hline & Médias & $74,2 \mathrm{a}$ & $73,3 \mathrm{a}$ & $73,7 \mathrm{a}$ & 73,7 & $71,6 a$ & $70,2 b$ & $68,2 \mathrm{c}$ & 70,0 \\
\hline
\end{tabular}

1 Médias seguidas pelas mesmas letras maiúsculas, nas colunas, e minúsculas, nas linhas, não diferem entre si pelo teste de Tukey a $5 \%$ de probabilidade. 
TABELA 3. Testes de envelhecimento acelerado (EA\%), de emergência (E \%), de comprimento de raiz (CR $\mathrm{cm})$ e de comprimento de plântula $(\mathrm{CP} \mathrm{cm})$ : dados médios, considerando as distâncias à entrada do ar insuflado e o tempo de secagem, em sementes de soja submetidas ao armazenamento. Ponta Grossa, PR, 19951.

\begin{tabular}{|c|c|c|c|c|c|c|c|c|c|}
\hline \multirow[t]{3}{*}{ Teste } & \multirow{3}{*}{$\begin{array}{c}\text { Tempo } \\
\text { de } \\
\text { secagem } \\
\text { (hora) }\end{array}$} & \multicolumn{4}{|c|}{0 mês } & \multicolumn{4}{|c|}{6 meses } \\
\hline & & \multicolumn{3}{|c|}{ Distâncias } & \multirow[b]{2}{*}{ Médias } & \multicolumn{3}{|c|}{ Distâncias } & \multirow[b]{2}{*}{ Médias } \\
\hline & & $\mathrm{D}_{1}$ & $\mathrm{D}_{2}$ & $\mathrm{D}_{3}$ & & $\mathrm{D}_{1}$ & $\mathrm{D}_{2}$ & $\mathrm{D}_{3}$ & \\
\hline \multirow[t]{5}{*}{ EA \% } & 0 & $77,6 \mathrm{Ba}$ & $77,5 \mathrm{Ba}$ & $78,1 \mathrm{Aa}$ & $77,7 \mathrm{~B}$ & $70,6 \mathrm{Cb}$ & $72,3 \mathrm{Bab}$ & $74,7 \mathrm{ABa}$ & $72,5 \mathrm{~B}$ \\
\hline & 4 & $81,2 \mathrm{Aa}$ & $79,3 \mathrm{ABab}$ & $78,2 \mathrm{Ab}$ & $79,6 \mathrm{~A}$ & $76,5 \mathrm{Aa}$ & $76,3 \mathrm{Aa}$ & $73,6 \mathrm{ABb}$ & $75,5 \mathrm{~A}$ \\
\hline & 8 & $80,4 \mathrm{Aab}$ & $81,3 \mathrm{Aa}$ & $79,2 \mathrm{Ab}$ & $80,3 \mathrm{~A}$ & $74,0 \mathrm{ABa}$ & $74,9 \mathrm{ABa}$ & $73,3 \mathrm{Ba}$ & $74,1 \mathrm{~A}$ \\
\hline & 12 & $80,8 \mathrm{Aa}$ & $81,0 \mathrm{Aa}$ & $80,2 \mathrm{Aa}$ & $80,7 \mathrm{~A}$ & $73,3 \mathrm{Bb}$ & 75,9Aa & $75,4 \mathrm{Aa}$ & $74,9 \mathrm{~A}$ \\
\hline & Médias & $80,0 \mathrm{a}$ & $79,8 \mathrm{a}$ & $78,9 \mathrm{a}$ & 79,6 & $73,6 \mathrm{a}$ & $74,8 \mathrm{a}$ & $74,3 \mathrm{a}$ & 74,2 \\
\hline \multirow[t]{5}{*}{$\mathrm{E} \%$} & 0 & $75,7 \mathrm{Ba}$ & $74,8 \mathrm{ABa}$ & $75,0 \mathrm{Aa}$ & $75,1 \mathrm{~A}$ & $56,1 \mathrm{Aa}$ & $54,2 \mathrm{Aa}$ & $56,1 \mathrm{Aa}$ & $55,5 \mathrm{~A}$ \\
\hline & 4 & $78,2 \mathrm{Aa}$ & $75,6 \mathrm{ABab}$ & $73,5 \mathrm{Ab}$ & $75,7 \mathrm{~A}$ & $54,9 \mathrm{Aa}$ & $55,1 \mathrm{Aa}$ & $54,7 \mathrm{Aa}$ & $54,9 \mathrm{~A}$ \\
\hline & 8 & $75,2 \mathrm{Bb}$ & $77,3 \mathrm{Aa}$ & $74,3 \mathrm{Ab}$ & $75,6 \mathrm{~A}$ & $54,4 \mathrm{Aa}$ & $55,3 \mathrm{Aa}$ & $52,9 \mathrm{Aa}$ & $54,2 \mathrm{~A}$ \\
\hline & 12 & $75,9 \mathrm{ABa}$ & $74,0 \mathrm{Ba}$ & $75,3 \mathrm{Aa}$ & $75,1 \mathrm{~A}$ & $53,9 \mathrm{Aa}$ & $55,9 \mathrm{Aa}$ & 55,9Aa & $55,2 \mathrm{~A}$ \\
\hline & Médias & $76,2 \mathrm{a}$ & $75,4 \mathrm{ab}$ & $74,5 \mathrm{~b}$ & 75,4 & $54,8 \mathrm{a}$ & $54,9 \mathrm{a}$ & $55,1 \mathrm{a}$ & 55,0 \\
\hline \multirow[t]{5}{*}{$\mathrm{CR} \mathrm{cm}$} & 0 & $15,8 \mathrm{Bb}$ & $16,4 \mathrm{Aa}$ & $16,4 \mathrm{Aa}$ & $16,2 \mathrm{~B}$ & $18,7 \mathrm{Aa}$ & $18,6 \mathrm{Aa}$ & $17,4 \mathrm{Ab}$ & $18,2 \mathrm{~A}$ \\
\hline & 4 & $17,0 \mathrm{ABa}$ & $16,8 \mathrm{Aa}$ & $16,6 \mathrm{Aa}$ & $16,8 \mathrm{AB}$ & $18,8 \mathrm{Aa}$ & $18,6 \mathrm{Aa}$ & $17,5 \mathrm{Ab}$ & $18,3 \mathrm{~A}$ \\
\hline & 8 & $17,3 \mathrm{Aa}$ & $17,3 \mathrm{Aa}$ & $17,3 \mathrm{Aa}$ & $17,3 \mathrm{~A}$ & $18,7 \mathrm{Aa}$ & $18,9 \mathrm{Aa}$ & $17,8 \mathrm{Ab}$ & $18,5 \mathrm{~A}$ \\
\hline & 12 & $17,1 \mathrm{ABa}$ & 17,3Aa & $17,5 \mathrm{Aa}$ & $17,3 \mathrm{~A}$ & 18,6Aa & $18,5 \mathrm{Aa}$ & $17,7 \mathrm{Ab}$ & $18,3 \mathrm{~A}$ \\
\hline & Médias & $16,6 \mathrm{a}$ & $16,9 \mathrm{a}$ & $17,0 \mathrm{a}$ & 16,9 & $18,7 \mathrm{a}$ & $18,6 \mathrm{a}$ & $17,6 \mathrm{~b}$ & 18,3 \\
\hline \multirow[t]{5}{*}{$\mathrm{CP} \mathrm{cm}$} & 0 & $21,0 \mathrm{Bb}$ & $22,0 \mathrm{Aa}$ & $22,0 \mathrm{Aa}$ & $21,7 \mathrm{~B}$ & $24,8 \mathrm{Aa}$ & $24,5 \mathrm{Aa}$ & $23,3 \mathrm{Ab}$ & $24,2 \mathrm{~A}$ \\
\hline & 4 & $22,6 \mathrm{ABa}$ & $22,5 \mathrm{Aa}$ & $22,1 \mathrm{Aa}$ & $22,4 \mathrm{AB}$ & $24,8 \mathrm{Aa}$ & 24,3Aab & $23,8 \mathrm{Ab}$ & $24,3 \mathrm{~A}$ \\
\hline & 8 & $23,5 \mathrm{Aa}$ & $23,0 \mathrm{Aa}$ & $22,9 \mathrm{Aa}$ & $23,1 \mathrm{~A}$ & $24,5 \mathrm{Aa}$ & $24,8 \mathrm{Aa}$ & $23,7 \mathrm{Ab}$ & $24,3 \mathrm{~A}$ \\
\hline & 12 & $22,9 \mathrm{Aa}$ & $23,0 \mathrm{Aa}$ & $23,2 \mathrm{Aa}$ & $23,0 \mathrm{~A}$ & $24,5 \mathrm{Aa}$ & $24,3 \mathrm{Aab}$ & $23,7 \mathrm{Ab}$ & $24,2 \mathrm{~A}$ \\
\hline & Médias & $22,5 \mathrm{a}$ & $22,7 \mathrm{a}$ & $22,5 \mathrm{a}$ & 22,6 & $24,7 \mathrm{a}$ & $24,5 \mathrm{a}$ & $23,6 b$ & 24,2 \\
\hline
\end{tabular}

Os dados de desempenho fisiológico das sementes, relacionados aos efeitos imediatos (0 mês) e latentes (seis meses) provocados pelos fluxos e temperaturas do ar insuflado, estão apresentados nas Tabelas 5 e 6. Quando individualmente interpreta- dos, os testes indicaram ações interativas dos tratamentos com tendências pouco consistentes.

Por esse motivo, objetivando facilitar a interpretação dos dados, as interações foram estudadas (Tabelas 7 e 8) considerando o número e a freqüên- 
TABELA 4. Dados da temperatura do ar da massa de sementes de soja obtidos durante secagens estacionárias conduzidas sob $42^{\circ} \mathrm{C}, 46^{\circ} \mathrm{C}$ e $50^{\circ} \mathrm{C}$ com variações no fluxo do ar insuflado. Ponta Grossa, PR, $1995^{1}$

\begin{tabular}{|c|c|c|c|c|c|c|c|c|c|c|c|c|c|c|c|}
\hline \multirow{3}{*}{$\begin{array}{c}\mathrm{F} \\
\left(\mathrm{m}^{3} / \mathrm{minuto} / \mathrm{t}\right)\end{array}$} & \multirow{3}{*}{$\begin{array}{c}\mathrm{T} \\
\left({ }^{\circ} \mathrm{C}\right)\end{array}$} & \multirow{3}{*}{$\begin{array}{c}\text { TS } \\
\text { (hora) }\end{array}$} & \multirow{2}{*}{\multicolumn{3}{|c|}{$\begin{array}{c}\text { Massa de sementes }\left(\mathrm{t}^{\circ} \mathrm{C}\right) \\
\text { Distâncias }\end{array}$}} & \multirow{3}{*}{$\begin{array}{c}\mathrm{T} \\
\left({ }^{\circ} \mathrm{C}\right)\end{array}$} & \multirow{3}{*}{$\begin{array}{c}\text { TS } \\
\text { (hora) }\end{array}$} & \multirow{2}{*}{\multicolumn{3}{|c|}{$\begin{array}{c}\text { Massa de sementes }\left(\mathrm{t}^{\circ} \mathrm{C}\right) \\
\text { Distâncias }\end{array}$}} & \multirow{3}{*}{$\begin{array}{c}\mathrm{T} \\
\left({ }^{\circ} \mathrm{C}\right)\end{array}$} & \multirow{3}{*}{$\begin{array}{c}\text { TS } \\
\text { (hora) }\end{array}$} & \multirow{2}{*}{\multicolumn{3}{|c|}{$\begin{array}{c}\text { Massa de sementes }\left(\mathrm{t}^{\circ} \mathrm{C}\right) \\
\text { Distâncias }\end{array}$}} \\
\hline & & & & & & & & & & & & & & & \\
\hline & & & D1 & D2 & D3 & & & D1 & D2 & D3 & & & D1 & D2 & D3 \\
\hline \multirow[t]{7}{*}{26,9} & 42 & 0,0 & 22,3 & 22,5 & 22,0 & 46 & 0,0 & 27,7 & 28,8 & 26,0 & 50 & 0,0 & 25,6 & 25,7 & 24,5 \\
\hline & & 2,0 & 31,5 & 27,1 & 26,5 & & 2,0 & 39,5 & 30,6 & 30,3 & & 2,0 & 41,7 & 31,7 & 31,7 \\
\hline & & 4,0 & 36,6 & 27,3 & 26,7 & & 4,0 & 41,3 & 34,1 & 30,4 & & 4,0 & 46,3 & 35,8 & 31,9 \\
\hline & & 6,0 & 39,9 & 29,4 & 26,5 & & 6,0 & 42,5 & 37,7 & 30,3 & & 6,0 & 49,1 & 40,9 & 32,5 \\
\hline & & 8,0 & 39,8 & 32,8 & 25,6 & & 8,0 & 44,1 & 38,5 & 31,3 & & 8,0 & 47,9 & 42,7 & 32,9 \\
\hline & & 10,0 & 39,6 & 35,3 & 26,7 & & 10,0 & 44,0 & 40,8 & 33,3 & & 10,0 & 49,0 & 44,2 & 34,8 \\
\hline & & 12,0 & 38,4 & 34,8 & 26,6 & & 12,0 & 45,7 & 41,9 & 35,9 & & 12,0 & 48,5 & 44,3 & 36,5 \\
\hline \multirow[t]{7}{*}{28,4} & 42 & 0,0 & 23,1 & 23,2 & 21,8 & 46 & 0,0 & 22,2 & 22,4 & 19,8 & 50 & 0,0 & 19,4 & 19,6 & 18,0 \\
\hline & & 2,0 & 35,1 & 25,7 & 25,2 & & 2,0 & 35,9 & 25,9 & 25,5 & & 2,0 & 40,4 & 27,9 & 26,7 \\
\hline & & 4,0 & 38,1 & 30,0 & 25,2 & & 4,0 & 40,0 & 20,8 & 24,6 & & 4,0 & 44,3 & 33,9 & 27,6 \\
\hline & & 6,0 & 38,8 & 34,1 & 26,3 & & 6,0 & 42,1 & 32,6 & 24,3 & & 6,0 & 46,3 & 38,6 & 29,3 \\
\hline & & 8,0 & 39,6 & 35,8 & 28,3 & & 8,0 & 42,5 & 36,3 & 26,7 & & 8,0 & 46,0 & 41,4 & 32,3 \\
\hline & & 10,0 & 40,0 & 36,8 & 30,4 & & 10,0 & 43,6 & 37,7 & 30,0 & & 10,0 & 47,8 & 42,9 & 34,1 \\
\hline & & 12,0 & 40,8 & 37,3 & 32,1 & & 12,0 & 42,2 & 38,8 & 31,0 & & 12,0 & 46,8 & 44,0 & 36,1 \\
\hline \multirow[t]{7}{*}{33,2} & 42 & 0,0 & 21,6 & 21,7 & 20,2 & 46 & 0,0 & 22,8 & 22,8 & 21,9 & 50 & 0,0 & 21,9 & 21,9 & 21,4 \\
\hline & & 2,0 & 37,5 & 28,2 & 26,5 & & 2,0 & 39,5 & 31,2 & 29,0 & & 2,0 & 42,3 & 31,0 & 29,2 \\
\hline & & 4,0 & 39,1 & 33,9 & 26,5 & & 4,0 & 40,8 & 36,4 & 30,2 & & 4,0 & 43,7 & 37,1 & 29,5 \\
\hline & & 6,0 & 39,8 & 36,5 & 29,7 & & 6,0 & 41,6 & 38,6 & 32,9 & & 6,0 & 43,3 & 40,2 & 32,8 \\
\hline & & 8,0 & 41,4 & 38,6 & 33,2 & & 8,0 & 43,1 & 40,7 & 35,9 & & 8,0 & 45,6 & 41,7 & 36,7 \\
\hline & & 10,0 & 40,2 & 39,0 & 34,7 & & 10,0 & 42,5 & 40,7 & 36,6 & & 10,0 & 46,1 & 44,2 & 39,6 \\
\hline & & 12,0 & 39,3 & 38,0 & 35,5 & & 12,0 & 42,1 & 41,2 & 38,3 & & 12,0 & 45,1 & 43,7 & 40,4 \\
\hline
\end{tabular}

${ }^{1}$ F: fluxo de ar insuflado; $T$ : temperatura; TS: tempo de secagem; $D_{1}, D_{2}, D_{3}$ : distâncias radiais em relação ao cilindro central de insuflação de ar. 
TABELA 5. Testes de germinação (G\%), condutividade elétrica (CE G\%), de tetrazólio germinação (TZG\%) e de tetrazólio vigor (TZV\%): dados médios, considerando os fluxos e as temperaturas do ar insuflado na secagem, em sementes de soja submetidas ao armazenamento. Ponta Grossa, PR, $1995^{1}$.

\begin{tabular}{|c|c|c|c|c|c|c|c|c|c|}
\hline \multirow[t]{3}{*}{ Teste } & \multirow{3}{*}{$\begin{array}{c}\text { Fluxo } \\
\left(\mathrm{m}^{3} / \mathrm{minuto} / \mathrm{t}\right)\end{array}$} & \multicolumn{4}{|c|}{0 mês } & \multicolumn{4}{|c|}{6 meses } \\
\hline & & \multicolumn{3}{|c|}{ Temperatura } & \multirow[t]{2}{*}{ Médias } & \multicolumn{3}{|c|}{ Temperatura } & \multirow[t]{2}{*}{ Médias } \\
\hline & & $42^{\circ} \mathrm{C}$ & $46^{\circ} \mathrm{C}$ & $50^{\circ} \mathrm{C}$ & & $42^{\circ} \mathrm{C}$ & $46^{\circ} \mathrm{C}$ & $50^{\circ} \mathrm{C}$ & \\
\hline \multirow[t]{4}{*}{$\mathrm{G} \%$} & 26,9 & $88,0 \mathrm{Bb}$ & $92,3 \mathrm{Aa}$ & $91,2 \mathrm{Aa}$ & $90,5 \mathrm{~A}$ & $85,2 \mathrm{Bb}$ & $89,7 \mathrm{Aa}$ & $88,0 \mathrm{Aa}$ & $87,7 \mathrm{~A}$ \\
\hline & 28,4 & $89,1 \mathrm{ABa}$ & $88,1 \mathrm{Ba}$ & $89,5 \mathrm{Ba}$ & $88,9 \mathrm{~B}$ & $86,8 \mathrm{Ba}$ & $86,6 \mathrm{Ba}$ & $88,0 \mathrm{Aa}$ & $87,1 \mathrm{~A}$ \\
\hline & 33,2 & $90,5 \mathrm{Aa}$ & $90,8 \mathrm{Aa}$ & $83,7 \mathrm{Cb}$ & $88,3 \mathrm{~B}$ & $88,8 \mathrm{Ab}$ & $90,2 \mathrm{Aa}$ & $81,7 \mathrm{Bc}$ & $86,9 \mathrm{~A}$ \\
\hline & Médias & $89,2 \mathrm{~b}$ & $90,4 \mathrm{a}$ & $88,1 \mathrm{c}$ & 89,2 & $86,9 \mathrm{~b}$ & $88,8 \mathrm{a}$ & $85,9 \mathrm{c}$ & 87,2 \\
\hline \multirow[t]{4}{*}{ CE G \% } & 26,9 & $88,7 \mathrm{Ba}$ & $88,1 \mathrm{Ba}$ & $89,8 \mathrm{Aa}$ & $88,9 \mathrm{AB}$ & $82,9 \mathrm{Bb}$ & $81,8 \mathrm{Bb}$ & $86,3 \mathrm{Aa}$ & $83,7 \mathrm{~A}$ \\
\hline & 28,4 & $88,4 \mathrm{Ba}$ & $86,0 \mathrm{Bb}$ & $90,0 \mathrm{Aa}$ & $88,1 \mathrm{~B}$ & $85,8 \mathrm{Aa}$ & $81,4 \mathrm{Bb}$ & $83,5 \mathrm{Bab}$ & $83,6 \mathrm{~A}$ \\
\hline & 33,2 & 90,9Аа & $91,0 \mathrm{Aa}$ & $87,4 \mathrm{Bb}$ & $89,7 \mathrm{~A}$ & $88,1 \mathrm{Aa}$ & $87,1 \mathrm{Aa}$ & $77,4 \mathrm{Cb}$ & $84,2 \mathrm{~A}$ \\
\hline & Médias & $89,3 \mathrm{a}$ & $88,4 a$ & $89,0 \mathrm{a}$ & 88,9 & $85,6 \mathrm{a}$ & $83,4 \mathrm{~b}$ & $82,4 \mathrm{~b}$ & 83,8 \\
\hline \multirow[t]{4}{*}{ TZG \% } & 26,9 & $83,7 \mathrm{Ba}$ & $85,3 \mathrm{Aa}$ & $84,9 \mathrm{Aa}$ & $84,6 \mathrm{AB}$ & $83,3 \mathrm{Bb}$ & $85,5 \mathrm{Aab}$ & $85,9 \mathrm{Aa}$ & $84,9 \mathrm{~A}$ \\
\hline & 28,4 & $85,8 \mathrm{ABab}$ & $83,9 \mathrm{Ab}$ & $87,1 \mathrm{Aa}$ & $85,6 \mathrm{~A}$ & $85,7 \mathrm{Aa}$ & $83,8 \mathrm{ABb}$ & $85,8 \mathrm{Aa}$ & $85,1 \mathrm{~A}$ \\
\hline & 33,2 & $86,1 \mathrm{Aa}$ & $86,6 \mathrm{Aa}$ & $79,3 \mathrm{Bb}$ & $84,0 \mathrm{~B}$ & $84,4 \mathrm{ABa}$ & $82,9 \mathrm{Ba}$ & $77,4 \mathrm{Bb}$ & $81,5 \mathrm{~B}$ \\
\hline & Médias & $85,2 \mathrm{a}$ & $85,3 \mathrm{a}$ & $83,8 \mathrm{a}$ & 84,7 & $84,1 \mathrm{a}$ & $84,1 \mathrm{ab}$ & $83,0 \mathrm{~b}$ & 83,9 \\
\hline \multirow[t]{4}{*}{ TZV \% } & 26,9 & $73,4 \mathrm{Aa}$ & $72,6 \mathrm{Ba}$ & $74,8 \mathrm{Aa}$ & $73,6 \mathrm{AB}$ & $70,7 \mathrm{Aa}$ & $72,1 \mathrm{Aa}$ & $72,8 \mathrm{Aa}$ & $71,9 \mathrm{~A}$ \\
\hline & 28,4 & 74,7Aab & $73,2 \mathrm{Bb}$ & $76,3 \mathrm{Aa}$ & $74,7 \mathrm{~A}$ & $72,0 \mathrm{Aa}$ & $68,0 \mathrm{Bb}$ & $72,1 \mathrm{Aa}$ & $70,7 \mathrm{~A}$ \\
\hline & 33,2 & $75,4 \mathrm{Aa}$ & $77,7 \mathrm{Aa}$ & $65,3 \mathrm{Bb}$ & $72,8 \mathrm{~B}$ & $72,4 \mathrm{Aa}$ & $67,7 \mathrm{Bb}$ & $62,3 \mathrm{Bc}$ & $67,5 \mathrm{~B}$ \\
\hline & Médias & $74,5 \mathrm{a}$ & $74,5 \mathrm{a}$ & $72,1 \mathrm{~b}$ & 73,7 & $71,7 \mathrm{a}$ & $69,3 b$ & $69,1 \mathrm{~b}$ & 70,0 \\
\hline
\end{tabular}

1 Médias seguidas pelas mesmas letras maiúsculas, nas colunas, e minúsculas, nas linhas, não diferem entre si pelo teste de Tukey a 5\% de probabilidade.

cia das superioridades estatísticas encontradas no conjunto dos testes.

Quando fixada a temperatura de $50^{\circ} \mathrm{C}$ (Tabela 7), os fluxos de 26,9 e de $28,4 \mathrm{~m}^{3} /$ minuto/t superaram o de $33,2 \mathrm{~m}^{3} /$ minuto/t, respectivamente, em $87,5 \%$ e $93,75 \%$ dos casos. Nas demais temperaturas, as freqüências das superioridades foram menores do que $50 \%$, e, dessa forma, não evidenciaram diferenças entre os efeitos dos fluxos sobre a qualidade das sementes.

Fixando o fluxo de $33,2 \mathrm{~m}^{3} /$ minuto/t (Tabela 8), as temperaturas de 42 e $46^{\circ} \mathrm{C}$ superaram a de $50^{\circ} \mathrm{C}$, respectivamente, em $87,5 \%$ e $81,25 \%$ dos casos. Nos outros fluxos, as frequiências das superioridades foram inferiores a $50 \%$ e, dessa maneira, não destacaram diferenças entre as interferências das temperaturas sobre o desempenho das sementes.

Assim, os usos associados dos menores fluxos (26,9 e $\left.28,4 \mathrm{~m}^{3} / \mathrm{minuto} / \mathrm{t}\right)$ com a maior temperatura $\left(50^{\circ} \mathrm{C}\right)$ e das menores temperaturas $\left(42\right.$ e $\left.46^{\circ} \mathrm{C}\right) \mathrm{com}$ o maior fluxo $\left(33,2 \mathrm{~m}^{3} /\right.$ minuto/t), atenuaram a deterioração decorrente da operação de secagem; paralelamente, indicaram que os efeitos positivos das elevações no fluxo foram favorecidos com as reduções de temperatura e vice-versa. 
TABELA 6. Testes de envelhecimento acelerado (EA\%), de emergência (E\%), de comprimento de raiz (CR $\mathrm{cm})$ e de comprimento de plântula $(\mathrm{CP} \mathrm{cm})$ : dados médios, considerando os fluxos e as temperaturas do ar insuflado na secagem, em sementes de soja submetidas ao armazenamento. Ponta Grossa, PR, 1995 .

\begin{tabular}{|c|c|c|c|c|c|c|c|c|c|}
\hline \multirow[t]{3}{*}{ Teste } & \multirow{3}{*}{$\begin{array}{c}\text { Fluxo } \\
\left(\mathrm{m}^{3} / \mathrm{minuto} / \mathrm{t}\right)\end{array}$} & \multicolumn{4}{|c|}{0 mês } & \multicolumn{4}{|c|}{6 meses } \\
\hline & & \multicolumn{3}{|c|}{ Temperatura } & \multirow[t]{2}{*}{ Médias } & \multicolumn{3}{|c|}{ Temperatura } & \multirow[t]{2}{*}{ Médias } \\
\hline & & $42^{\circ} \mathrm{C}$ & $46^{\circ} \mathrm{C}$ & $50^{\circ} \mathrm{C}$ & & $42^{\circ} \mathrm{C}$ & $46^{\circ} \mathrm{C}$ & $50^{\circ} \mathrm{C}$ & \\
\hline \multirow[t]{4}{*}{ EA $\%$} & 26,9 & $79,0 \mathrm{Ab}$ & $86,4 \mathrm{Aa}$ & $80,2 \mathrm{Ab}$ & $81,9 \mathrm{~A}$ & $72,8 \mathrm{Bb}$ & $79,0 \mathrm{Aa}$ & $77,8 \mathrm{Aa}$ & $76,5 \mathrm{~A}$ \\
\hline & 28,4 & 78,9Aa & $78,3 \mathrm{Ca}$ & $80,8 \mathrm{Aa}$ & $79,3 \mathrm{~B}$ & $76,6 \mathrm{Aa}$ & $72,2 \mathrm{Bb}$ & $73,4 \mathrm{Bb}$ & $74,1 \mathrm{~B}$ \\
\hline & 33,2 & $81,9 \mathrm{Aa}$ & $82,4 \mathrm{Ba}$ & $68,2 \mathrm{Bb}$ & $77,5 \mathrm{C}$ & $78,1 \mathrm{Aa}$ & 77,9Aa & $60,4 \mathrm{Cb}$ & $72,1 \mathrm{C}$ \\
\hline & Médias & $79,9 \mathrm{~b}$ & $82,4 \mathrm{a}$ & $76,4 \mathrm{c}$ & 79,6 & $75,8 \mathrm{a}$ & $76,4 \mathrm{a}$ & $70,5 b$ & 74,2 \\
\hline \multirow[t]{4}{*}{ E \% } & 26,9 & $75,0 \mathrm{Ac}$ & $81,9 \mathrm{Aa}$ & $78,3 \mathrm{Ab}$ & $78,4 \mathrm{~A}$ & $59,5 \mathrm{Aa}$ & $58,6 \mathrm{Aa}$ & $58,1 \mathrm{Aa}$ & $58,7 \mathrm{~A}$ \\
\hline & 28,4 & 75,9Aa & $73,0 \mathrm{Bb}$ & $75,9 \mathrm{Ba}$ & $74,9 \mathrm{~B}$ & $58,6 \mathrm{Aa}$ & $57,4 \mathrm{Aa}$ & $56,1 \mathrm{Aa}$ & $57,7 \mathrm{~A}$ \\
\hline & 33,2 & $76,4 \mathrm{Aa}$ & $76,5 \mathrm{Ba}$ & $65,8 \mathrm{Cb}$ & $72,9 \mathrm{C}$ & $54,3 \mathrm{Aa}$ & $45,2 \mathrm{Bb}$ & $46,7 \mathrm{Bb}$ & $48,8 \mathrm{~B}$ \\
\hline & Médias & $75,8 \mathrm{a}$ & $77,1 \mathrm{a}$ & $73,3 b$ & 75,4 & $57,5 \mathrm{a}$ & $53,7 \mathrm{~b}$ & $53,6 \mathrm{~b}$ & 55,0 \\
\hline \multirow[t]{4}{*}{$\mathrm{CR} \mathrm{cm}$} & 26,9 & $17,4 \mathrm{Aa}$ & $15,6 \mathrm{Bb}$ & $15,8 \mathrm{Cb}$ & $16,3 \mathrm{C}$ & $19,0 \mathrm{Aa}$ & $18,7 \mathrm{Aa}$ & $17,9 \mathrm{Ab}$ & $18,5 \mathrm{~A}$ \\
\hline & 28,4 & $15,8 \mathrm{Bb}$ & $19,0 \mathrm{Aa}$ & $18,6 \mathrm{Aa}$ & $17,8 \mathrm{~A}$ & $18,5 \mathrm{Aa}$ & $18,7 \mathrm{Aa}$ & $17,9 \mathrm{ABa}$ & $18,4 \mathrm{AB}$ \\
\hline & 33,2 & $15,9 \mathrm{Bb}$ & $16,0 \mathrm{Bb}$ & $18,0 \mathrm{Ba}$ & $16,6 \mathrm{~B}$ & $18,8 \mathrm{Aa}$ & $18,1 \mathrm{Ab}$ & $17,3 \mathrm{Bc}$ & $18,1 \mathrm{~B}$ \\
\hline & Médias & $16,4 \mathrm{a}$ & $16,8 \mathrm{a}$ & $17,4 \mathrm{a}$ & 16,9 & $18,8 \mathrm{a}$ & $18,5 \mathrm{a}$ & $17,7 \mathrm{~b}$ & 18,3 \\
\hline \multirow[t]{4}{*}{$\mathrm{CP} \mathrm{cm}$} & 26,9 & $23,8 \mathrm{Aa}$ & $20,8 \mathrm{Bb}$ & $21,2 \mathrm{Cb}$ & $22,0 \mathrm{~B}$ & $25,4 \mathrm{Aa}$ & $24,8 \mathrm{ABa}$ & $23,5 \mathrm{Ab}$ & $24,5 \mathrm{~A}$ \\
\hline & 28,4 & $21,6 \mathrm{Bc}$ & $25,9 \mathrm{Aa}$ & $25,0 \mathrm{Ab}$ & $24,2 \mathrm{~A}$ & $24,5 \mathrm{Bab}$ & $25,1 \mathrm{Aa}$ & $23,8 \mathrm{Ab}$ & $24,4 \mathrm{~A}$ \\
\hline & 33,2 & $20,6 \mathrm{Bb}$ & $20,9 \mathrm{Bb}$ & $23,2 \mathrm{Ba}$ & $21,6 \mathrm{~B}$ & $24,5 \mathrm{Ba}$ & $24,1 \mathrm{Ba}$ & $22,8 \mathrm{Bb}$ & $23,8 \mathrm{~B}$ \\
\hline & Médias & $22,0 \mathrm{c}$ & $22,5 b$ & $23,2 \mathrm{a}$ & 22,6 & $24,8 \mathrm{a}$ & $24,6 \mathrm{a}$ & $23,3 b$ & 24,2 \\
\hline
\end{tabular}

${ }^{1}$ Médias seguidas pelas mesmas letras maiúsculas, nas colunas, e minúsculas, nas linhas, não diferem entre si pelo teste de Tukey a $5 \%$ de probabilidade.

Os dados de velocidade de secagem, confirmados pelas curvas obtidas quanto à perda de água (Miranda et al.,1999), indicaram vantagens físicas operacionais na situação em que foram aplicados a temperatura e o fluxo intermediários $\left(46^{\circ} \mathrm{C}\right.$ e $28,4 \mathrm{~m}^{3} /$ minuto/t) no ar insuflado. Por outro lado, sob o aspecto de manutenção da qualidade fisiológica, as combinações dos menores fluxos $\left(26,9\right.$ e $28,4 \mathrm{~m}^{3} /$ minuto/t) com a maior temperatura $\left(50^{\circ} \mathrm{C}\right)$ e das menores temperaturas $\left(42\right.$ e $\left.46^{\circ} \mathrm{C}\right)$ com o maior fluxo $\left(33,2 \mathrm{~m}^{3} /\right.$ minuto/t) foram as mais vantajosas; dentre essas, levando em conta os aspectos físico-operacionais, a associação de $28,4 \mathrm{~m}^{3} /$ minuto/t com $50^{\circ} \mathrm{C}$ foi a mais eficiente na retirada de água das sementes.

A interdependência na ação de fluxos e de temperaturas do ar insuflado, no que se relaciona às conseqüências físicas e fisiológicas impostas às sementes submetidas à secagem, é assunto pouco esclarecido pela literatura para embasar as recomendações tecnológicas que, dessa maneira, são formuladas com tendências de unilateralidade em sua base de sustentação. Os resultados obtidos ressaltam a importância da consideração do conjunto de fatores intervenientes no processo em estudos sobre o assunto. 
TABELA 7. Ocorrências (no e freqüência) de superioridades com apoio estatístico, verificadas nos testes de avaliação da qualidade fisiológica, com a fixação das temperaturas nas interações entre fluxo e temperatura do ar insuflado. Ponta Grossa, PR, 1995.

\begin{tabular}{|c|c|c|c|c|c|}
\hline \multirow[t]{2}{*}{$\begin{array}{l}\text { Causa fixada } \\
\text { (temperatura) }\end{array}$} & \multirow[t]{2}{*}{ Superioridade } & \multicolumn{3}{|c|}{$\begin{array}{c}\text { Ocorrências }\left(\mathrm{n}^{\circ}\right) \text { durante o } \\
\text { armazenamento }\end{array}$} & \multirow{2}{*}{$\begin{array}{l}\text { Frequiência }(\%) \text { das } \\
\text { ocorrências no total } \\
\text { das } 16 \text { possíveis } \\
\text { (8 testes } x 2 \text { épocas) }\end{array}$} \\
\hline & & $\begin{array}{c}\text { Imediatos } \\
\text { (0 mês })\end{array}$ & $\begin{array}{l}\text { Latentes } \\
\text { (6 meses) }\end{array}$ & Somatório & \\
\hline \multirow[t]{6}{*}{$42^{\circ} \mathrm{C}$} & $26,9>28,4 \mathrm{~m}^{3} /$ minuto $/ \mathrm{t}$ & 2 & 1 & 3 & 18,75 \\
\hline & $26,9>33,2 \mathrm{~m}^{3} /$ minuto $/ \mathrm{t}$ & 2 & 1 & 3 & 18,75 \\
\hline & $28,4>26,9 \mathrm{~m}^{3} /$ minuto $/ \mathrm{t}$ & 0 & 3 & 3 & 18,75 \\
\hline & $28,4>33,2 \mathrm{~m}^{3} /$ minuto $/ \mathrm{t}$ & 0 & 1 & 1 & 6,25 \\
\hline & $33,2>26,9 \mathrm{~m}^{3} /$ minuto $/ \mathrm{t}$ & 3 & 3 & 6 & 37,50 \\
\hline & $33,2>28,4 \mathrm{~m}^{3} /$ minuto/t & 2 & 1 & 3 & 18,75 \\
\hline \multirow[t]{6}{*}{$46^{\circ} \mathrm{C}$} & $26,9>28,4 \mathrm{~m}^{3} /$ minuto $/ \mathrm{t}$ & 3 & 3 & 6 & 37,50 \\
\hline & $26,9>33,2 \mathrm{~m}^{3} /$ minuto $/ \mathrm{t}$ & 2 & 3 & 5 & 31,25 \\
\hline & $28,4>26,9 \mathrm{~m}^{3} /$ minuto $/ \mathrm{t}$ & 2 & 0 & 2 & 12,50 \\
\hline & $28,4>33,2 \mathrm{~m}^{3} /$ minuto $/ \mathrm{t}$ & 2 & 2 & 4 & 25,00 \\
\hline & $33,2>26,9 \mathrm{~m}^{3} /$ minuto $/ \mathrm{t}$ & 2 & 1 & 3 & 18,75 \\
\hline & $33,2>28,4 \mathrm{~m}^{3} /$ minuto/t & 4 & 3 & 7 & 43,75 \\
\hline \multirow[t]{6}{*}{$50^{\circ} \mathrm{C}$} & $26,9>28,4 \mathrm{~m}^{3} /$ minuto/t & 2 & 2 & 4 & 25,00 \\
\hline & $26,9>33,2 \mathrm{~m}^{3} /$ minuto/t & 6 & 8 & 14 & 87,50 \\
\hline & $28,4>26,9 \mathrm{~m}^{3} /$ minuto $/ \mathrm{t}$ & 2 & 0 & 2 & 12,50 \\
\hline & $28,4>33,2 \mathrm{~m}^{3} /$ minuto $/ \mathrm{t}$ & 8 & 7 & 15 & 93,75 \\
\hline & $33,2>26,9 \mathrm{~m}^{3} /$ minuto $/ \mathrm{t}$ & 2 & 0 & 2 & 12,50 \\
\hline & $33,2>28,4 \mathrm{~m}^{3} /$ minuto/t & 0 & 0 & 0 & 0,00 \\
\hline
\end{tabular}


TABELA 8. Ocorrências (no e freqüência) de superioridades com apoio estatístico, verificadas nos testes de avaliação da qualidade fisiológica, com a fixação dos fluxos nas interações entre fluxo e temperatura do ar insuflado. Ponta Grossa, PR, 1995.

\begin{tabular}{|c|c|c|c|c|c|}
\hline \multirow{2}{*}{$\begin{array}{l}\text { Causa fixada } \\
\text { (fluxo) }\end{array}$} & \multirow[t]{2}{*}{ Superioridade } & \multicolumn{3}{|c|}{ Ocorrências $\left(\mathrm{n}^{\circ}\right)$ durante $\mathrm{o}$ armazenamento } & \multirow{2}{*}{$\begin{array}{l}\text { Frequiência }(\%) \text { das } \\
\text { ocorrências no total } \\
\text { das } 16 \text { possíveis } \\
\text { (8 testes x } 2 \text { épocas) }\end{array}$} \\
\hline & & $\begin{array}{l}\text { Imediatos } \\
\text { (0 mês })\end{array}$ & $\begin{array}{l}\text { Latentes } \\
\text { (6 meses) }\end{array}$ & Somatório & \\
\hline \multirow[t]{6}{*}{$26,9 \mathrm{~m}^{3} / \mathrm{minuto} / \mathrm{t}$} & $42^{\circ} \mathrm{C}>46^{\circ} \mathrm{C}$ & 2 & 0 & 2 & 12,50 \\
\hline & $42^{\circ} \mathrm{C}>50^{\circ} \mathrm{C}$ & 2 & 2 & 4 & 25,00 \\
\hline & $46^{\circ} \mathrm{C}>42^{\circ} \mathrm{C}$ & 3 & 2 & 5 & 31,25 \\
\hline & $46^{\circ} \mathrm{C}>50^{\circ} \mathrm{C}$ & 2 & 2 & 4 & 25,00 \\
\hline & $50^{\circ} \mathrm{C}>42^{\circ} \mathrm{C}$ & 2 & 4 & 6 & 37,50 \\
\hline & $50^{\circ} \mathrm{C}>46^{\circ} \mathrm{C}$ & 0 & 1 & 1 & 6,25 \\
\hline \multirow[t]{6}{*}{$28,4 \mathrm{~m}^{3} / \mathrm{minuto} / \mathrm{t}$} & $42^{\circ} \mathrm{C}>46^{\circ} \mathrm{C}$ & 2 & 4 & 6 & 37,50 \\
\hline & $42^{\circ} \mathrm{C}>50^{\circ} \mathrm{C}$ & 0 & 1 & 1 & 6,25 \\
\hline & $46^{\circ} \mathrm{C}>42^{\circ} \mathrm{C}$ & 2 & 0 & 2 & 12,50 \\
\hline & $46^{\circ} \mathrm{C}>50^{\circ} \mathrm{C}$ & 1 & 1 & 2 & 12,50 \\
\hline & $50^{\circ} \mathrm{C}>42^{\circ} \mathrm{C}$ & 2 & 0 & 2 & 12,50 \\
\hline & $50^{\circ} \mathrm{C}>46^{\circ} \mathrm{C}$ & 4 & 2 & 6 & 37,50 \\
\hline \multirow[t]{6}{*}{$33,2 \mathrm{~m}^{3} / \mathrm{minuto} / \mathrm{t}$} & $42^{\circ} \mathrm{C}>46^{\circ} \mathrm{C}$ & 0 & 3 & 3 & 18,75 \\
\hline & $42^{\circ} \mathrm{C}>50^{\circ} \mathrm{C}$ & 6 & 8 & 14 & 87,50 \\
\hline & $46^{\circ} \mathrm{C}>42^{\circ} \mathrm{C}$ & 0 & 1 & 1 & 6,25 \\
\hline & $46^{\circ} \mathrm{C}>50^{\circ} \mathrm{C}$ & 6 & 7 & 13 & 81,25 \\
\hline & $50^{\circ} \mathrm{C}>42^{\circ} \mathrm{C}$ & 2 & 0 & 2 & 12,50 \\
\hline & $50^{\circ} \mathrm{C}>46^{\circ} \mathrm{C}$ & 2 & 0 & 2 & 12,50 \\
\hline
\end{tabular}

\section{CONCLUSÃo}

Admitindo os intervalos de 26,9 a $33,2 \mathrm{~m}^{3} / \mathrm{minu}-$ to/t, para o fluxo, e de 42 a $50^{\circ} \mathrm{C}$, para a temperatura do ar insuflado radialmente durante a secagem das sementes de soja em silos, a elevação na temperatura demanda redução no fluxo e, inversamente, o aumento no fluxo, demanda redução na temperatura.

\section{REFERÊNCIAS}

AGRO SCIENCES. The automatic seed analyzers: Instruction Manual, models ASA-220, ASA-610 Ann Arbor, MI: Michigan Interface, 1979. 32p.
BOYD, A.H. Heated air drying of soybean (Glycine $\max ($ (L.) Merrill) seed. Mississippi: Mississippi State University, 1974. 90p. Ph.D. Thesis.

BRANDENBURG, N.R.; SIMONS, J.W.; SMITH, L.L. Why and how seeds are dried. In: THE UNITED STATES DEPARTMENT OF AGRICULTURE. Seeds The Yearbook of Agriculture 1961. Washington: The United States Government Printing Office, 1961. p.295-306.

BRASIL. Ministério da Agricultura. Secretaria Nacional de Defesa Agropecuária. Regras para análise de sementes. Brasília, 1992. 365p 
BROOKER, D.B.; BAKKER-ARKEMA, F.W.; HALL, C.W. Drying cereal grains. Westport: AVI, 1974 $265 \mathrm{p}$

CARVALHO, N.M. A secagem de sementes. Jaboticabal: FUNEP, 1994. 165p.

CAVARIANI, C. Secagem estacionária de sementes de milho com distribuição radial do fluxo de ar Piracicaba: USP-ESALQ, 1996. 85p. Tese de Doutorado

CHEN, Y.; BURRIS, J.S. Role of carbohydrates in desiccation tolerance and membrane behavior in maturing maize seed. Crop Science, v.30, p.971-975, 1990.

CORRÊA, C.F. Secagem de sementes de arroz (Oryza sativa $\mathrm{L}$.) em silo secador com distribuição radial de ar. Pelotas: UFPel, 1981. 85p. Dissertação de Mestrado.

DANIELL, J.W.; CHAPPELL, W.E.; COUCH, H.B. Effect of sublethal and lethal temperatures on plant cells. Plant Physiology, v.44, p.1684-1689, 1969

DIAS, D.C.F. dos S. Testes de condutividade elétrica e de lixiviação de potássio para avaliação do vigor de sementes de soja. Piracicaba: USP-ESALQ, 1994. 136p. Tese de Doutorado.

FRANÇA NETO, J.B. Qualidade fisiológica de sementes de soja. In: FRANÇA NETO, J.B.; HENNING, A.A. Qualidades fisiológica e sanitária de sementes de soja. Londrina: Embrapa-CNPSo, 1984. p.1-24. (Embrapa-CNPSo. Circular técnica, 9)

FRANÇA NETO, J.B.; PEREIRA, L.A.G.; COSTA, N.P.; KRZYZANOWSKI, F.C.; HENNING, A.A. Metodologia do teste de tetrazólio em sementes de soja. Londrina: Embrapa-CNPSo, 1988. 60p. (Embrapa-CNPSo. Documentos, 32).

HERTER, U.; BURRIS, J.S. Changes in moisture, temperature, and quality of soybeans seed during high-temperaure drying. Canadian Journal of Plant Science, v.69, n.3, p.749-761, 1989a.

HERTER, U.; BURRIS, J.S. Effect of drying rate and temperature on drying injury of corn seed. Canadian Journal of Plant Science, v.69, n.3, p.763-774, 1989b.

HERTER, U.; BURRIS, J.S. Evaluating drying injury on corn seed with a conductivity test. Seed Science and Technology, v.17, p.625-638, 1989c
KOSTER, K.L.; LEOPOLD, A.C. Sugars and desiccation tolerance in seeds. Plant Physiology, v.88, p.829-832, 1988.

LASSERAN, J.C. Princípios gerais de secagem. Revista Brasileira de Armazenamento, v.3, n.3, p.17-45, 1978.

MARCOS FILHO, J. Teste de envelhecimento acelerado. In: VIEIRA, R.D.; CARVALHO, N.M. (Coords.). Testes de vigor em sementes. Jaboticabal: FUNEP, 1994. p.133-149.

McLEAN, K.A. Drying and combinable crops. Ipswich: Farming, 1980. 280p.

MIRANDA, L.C.; SILVA, W.R. da; CAVARIANI, C Secagem de sementes de soja em silo com distribuição radial do fluxo de ar. I. Monitoramento físico. Pesquisa Agropecuária Brasileira, Brasília, v.34, n.11, p.2097-2108, nov. 1999.

NAVRATIL, R.J.; BURRIS, J.S. The effect of drying temperature on corn seed quality. Canadian Journal of Plant Science, v.64, p.487-496,1984

PASIN, N.H. Secagem estática de sementes de soja. Informativo da Associação Brasileira de Tecnologia de Sementes, v.2, n.1, p.33-39, 1991.

PESKE, S.T.; AGUIRRE, R. Manual para operadores de beneficio de semillas (UBS). Cali: CIAT, 1987. $117 \mathrm{p}$.

PESKE, S.T.; BAUDET, L.M. Considerações sobre s e c a gem de s eme n tes. Vi ç o s a, M G : CENTREINAR, 1980. 19p.

ROBERTS, E.H. Physiology of ageing and its application to drying and storage. Seed Science and Technology, v.9, p.359-372, 1981.

ROBERTS, E.H. Storage environment and the control of viability. In: ROBERTS, E.H. (Ed.). Viability of seeds. Syracuse: Syracuse Univ. Press, 1972. Ch. 2, p. 14-58.

SEYEDIN, N.; BURRIS, J.S.; FLYNN, T.E. Physiological studies on the effects of drying temperatures on corn seed quality. Canadian Journal of Plant Science, v.64, p.497-504, 1984.

VILLA, G.L.; ROA, G. Secagem e armazenamento de soja industrial e sementes a granel. Campinas: Fundação Cargill, 1979. 64p.

Pesq. agropec. bras., Brasília, v.34, n.11, p.2109-2121, nov. 1999 